\title{
An analysis of the Grade 3 Department of Basic Education workbooks as curriculum tools
}

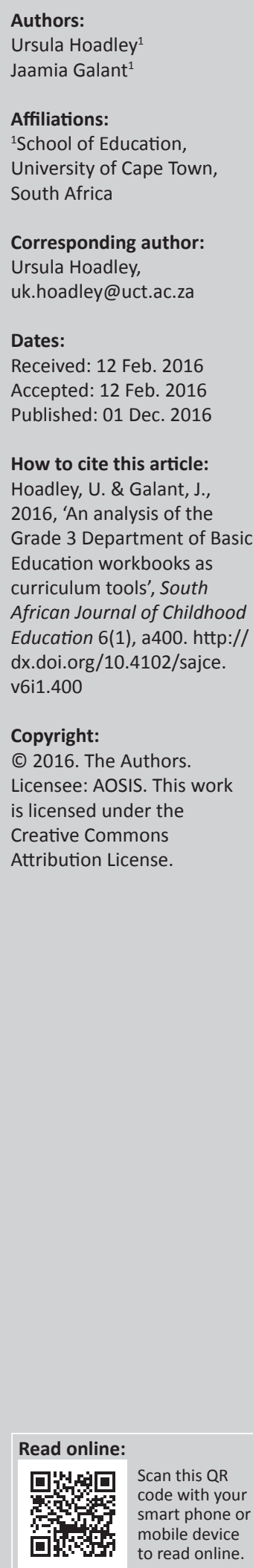

Since 2011, the Department of Basic Education (DBE), has provided all Grade 1 to 6 learners in public schools with literacy/language, numeracy/mathematics and life skills workbooks. This study provides an assessment of the purpose to which the workbooks are best suited by analysing the Grade 3 Mathematics and Home Language English workbooks for 2015 in the light of the DBE's intentions for the workbooks. The study considers alignment of the workbooks with the official national curriculum, the Curriculum and Assessment Policy (CAPS), as well as 'conceptual signalling' and progression in the content of the workbooks. We then evaluate the kind of 'curriculum tool' the workbooks in their current format conform to. We explore three possibilities in the light of the DBE's proposals for the workbook use: a practice tool; an assessment tool; and a monitoring tool. We also reflect on the workbooks as a teaching tool. Our analysis suggests that, in line with the DBE's intended purpose for the workbooks, that the workbooks best represent a practice curriculum tool. We highlight the significance of the high level of curriculum compliance of the workbook, and indicate that this would render them an effective monitoring tool for assessing the quantitative coverage of the curriculum at a systemic level.

\section{Introduction}

In 2011 the South African Department of Basic Education (DBE), responding to an injunction from the presidency, developed a set of workbooks, providing all Grade 1 to 6 learners in public schools with literacy/language and numeracy/mathematics workbooks. By 2015, the workbooks had been extended to include English first additional language and life skills (in the foundation phase). Workbooks are now available in all 11 languages from Grades R to 6 in the learning area of language. They are also available in all 11 languages for mathematics from Grade 1 to 3, and in English and Afrikaans from Grades 4 to 9. This is represented in the Table 1.

The development of the workbooks has been an enormous undertaking and has huge potential to improve teaching and learning in classrooms in South Africa. They currently reach 9 million learners in the system and provide teachers, especially in resource-poor settings, with systematic sets of colourful, worksheets to support the teaching of the curriculum. The importance of the workbooks, and their reported success thus far, led us to consider a small sample of the books in depth. The analysis focuses on the optimal uses of the workbooks given the ways in which they structure the curriculum knowledge at a particular grade level.

The workbooks have been revised each year, to align them with the official national curriculum, the Curriculum and Assessment Policy (CAPS) in 2012, and subsequently to eliminate errors and make quality revisions. According to the DBE website, the workbooks are intended 'to provide learners with worksheets to practice language and numeracy skills that they have been taught in class. They are also meant to help teachers track the progress of learners and provide extra support if needed. They are a simple way to structure learning activities for learners' (DBE 2015).

Given the scale of this intervention, the workbooks' widespread use, they have received significant policy attention as a curriculum intervention and their broader use has been raised. For example, suggestions have been made that they could provide the primary or sole resource in teaching mathematics and language. Or they could be used as a tool to monitor curriculum coverage at a system level. We are therefore interested in this paper in the nature of the workbooks as a curriculum tool. By curriculum tool, we mean a resource that supports the implementation of the curriculum. Do the workbooks conform to uses intended by the DBE? Are they potentially useful in ways other than specified by the DBE? The question of ascertaining what kind of tool the workbooks represented necessitated two sub-questions. The first was to what extent are the 
TABLE 1: Workbook subjects and language per grade 2015.

\begin{tabular}{llll}
\hline Grade & Home language & First additional language & Mathematics \\
\hline Grade R & All 11 languages & English & Life skills 11 languages (integrated book) \\
Grade 1-3 & All 11 languages & English & All 11 languages \\
Grade 4 & All 11 languages & English 11 languages & English \& Afrikaans \\
Grade 5 & All 11 languages & English & English \& Afrikaans \\
Grade 6 & All 11 languages & English & English \& Afrikaans \\
Grade 7 & - & - & English \& Afrikaans \\
Grade 8 & - & - & English \& Afrikaans \\
Grade 9 & - & - & English \& Afrikaans \\
\hline
\end{tabular}

workbooks aligned with the CAPS? As a curriculum tool, the extent of curriculum alignment would have key implications for the workbooks' use, especially as a curriculum 'practice' resource. Secondly, we addressed the structuring of content in the workbooks, looking specifically at 'conceptual signalling' and progression in the books. This enabled us to focus in particular on the workbooks as tools for monitoring, assessment and teaching.

There has as yet been little systematic study of the content of the workbooks. The few studies that have been done have focused on use. A study by Mathews et al. (2014) considered use of workbooks by six teachers. They found that workbooks were used for diverse purposes, including reinforcement of classwork, homework, demonstrating compliance with the demands of the education department and Annual National Assessment (ANA) preparation. Interestingly, in their paper they assume, following Fleisch et al.'s (2011) analysis of nonDBE workbooks, that the workbooks were designed by the DBE to ensure curriculum coverage. They recommend that the purposes of the workbook be spelt out more clearly.

The NEEDU 2012 (Taylor 2013) study reported on the distribution of workbooks and on teachers' responses to them. Overall the report concluded that the workbooks were widely used and well-received in most schools. The ACER report, in their sample of 290 schools, representative at the national level, also found widespread use of workbooks, generally reported to be used as supplementary to textbooks.

The Australian Council for Educational Research (2013) study also considered the content of the South African workbooks. Using a range of quality measures based on a review of the international literature, the report claimed that the workbooks were found to be quality workbooks. Unfortunately, there were serious threats to reliability and validity in this study in how judgments were made on the quality criteria. ${ }^{1}$ The only other investigations of workbook content formed part of the NEEDU 2012 and 2013 studies. Looking at the 2011 workbooks, the 2012 report concluded that 'workbooks do not provide nearly enough practice exercises in mathematics or opportunities for creative writing in language' (Taylor 2013). It is clear from our analysis that the workbooks have shifted substantially in relation to

1.For example, 'experts' were asked to make a judgment as to whether the workbooks 'Can be used effectively in classrooms', on a scale of 'not at all', 'to a minor extent', 'to a mo used effectivent', 'mo 'mo' is not made' 'to a major extent. What constituted "minor', 'major' ar 'moderate' is not made explicit nor exemplified, and it is not clear how judgments were made, and verified across experts. This is especially so in this case when the workbooks were not observed in use in classrooms. opportunities provided for writing practice, as we show below. The NEEDU 2013 study (that looked at 11 completed, consecutive pages in the Grade 5 First Additional Language workbook) found that the standard of students' actual responses was very low, inappropriate and very simplistic (Taylor 2014). Lastly, Davis (2012) and Galant (2013) in a very small sample of tasks, show subtle misconceptions embedded in some mathematics activities in the workbooks.

What this brief review indicates is that we have very limited research regarding the quality and nature of the content of the workbooks. Our study follows on from this initial work in analysing the Grade-3 mathematics and English home language (EHL) workbooks for 2015. The purpose of the workbooks, according to the DBE, is referred to above, and pertains to practice and to teacher monitoring of student work. In the light of this official intention around workbook use, our analysis aims to evaluate the extent to which the workbooks represent effective tools for practicing curriculum content and monitoring and assessing student work. We have interpreted 'track the progress of learners' in this context to mean not only monitoring of coverage but also a tool for assessment of learners' performance and progression.

We are considering the workbooks not from the perspective of the student and make no claims about whether they constitute an effective learning tool. Rather, we evaluate the workbooks as teacher (and possibly, system) tools. In the light of the DBE's proposed use, we explore three possibilities of workbooks as curriculum tools: (1) a practice tool; (2) an assessment tool; and (3) a monitoring tool. These are defined below. Evaluating the extent to which the workbooks conform to effective practice, assessment and monitoring tools has policy implications for their ongoing refinement and use. These implications are spelt out in the conclusion of the paper.

\section{Defining 'curriculum tools'}

There is a dearth of conceptual literature on the functions of pedagogic texts. Most of the literature on learning materials focuses on textbooks, and the function is generally assumed. Workbooks as a category of learning and teaching material, and what functions they may serve are neglected. There is an extensive literature that provides tools for the evaluation of texts, generating criteria and lists measuring the quality of texts on different dimensions (see Mukundan \& Ahour 2010 for a review). There is also a literature that focuses on the visual presentation and design of teaching and learning 
materials (Ulbig 2010, for example). Finally, there is a small literature on pedagogic approaches of teaching materials (addressing the issue of different learning styles, McLoughlin 1999, for example). We were interested in the specific function of workbooks as a curriculum tool, or a text that supported curriculum implementation. Through an initial engagement with the workbooks themselves, the intended purpose of the workbooks and the limited research on their use, we defined the three possibilities of the workbooks as curriculum tools: a practice tool, an assessment tool and a monitoring tool.

We define a practice tool as a text that provides opportunities for the rehearsal of concepts/concept/skills through tasks and activities. The practice tool may provide routine tasks, tasks that challenge and extend students or tasks that offer opportunities for remediation. Progression in relation to increasing complexity may be present if a wide range of contents over time is addressed.

An assessment tool provides tasks that cover a range of content, at different levels, and which are amenable to quantification in terms of the discrete content/concepts/ skills being assessed. An effective assessment tool makes the content/concepts/skills to be evaluated explicit and shows what constitutes an appropriate production (realised in model answers or rubrics etc.). An assessment tool would allow for monitoring learner performance and progression over time.

A monitoring tool ascertains how much curriculum content is being covered and at what levels of cognitive demand. In this regard, a monitoring tool would require strong alignment with the curriculum and explicit content progression.

While a practice and an assessment tool as defined above would be effective curriculum tools at the level of the classroom, i.e. used by the teacher, a monitoring tool, as defined above, may also be used as an effective curriculum tool at a systemic level.

Below we outline the sample, conceptual framework and methodology we undertook to evaluate the extent to which the workbooks conform to these curriculum tools.

\section{Sample}

In order to conduct an in-depth analysis of the workbooks we sampled the two 2015 Grade-3 EHL and two Grade-3 mathematics workbooks in their entirety. We selected Grade 3 as a critical point as the summation of the foundation phase. At this level, reading, writing and number concept are still explicitly taught. But students are being prepared in language to shift from learning to read to reading to learn, and from learning to write to writing extended texts in a range of formats. In mathematics in Grade 3, students are being prepared to shift from learning to become numerate and describe mathematical patterns, to becoming more fluent in calculations and engaging in more complex mathematical reasoning at the intermediate phase level.
Findings are limited in that only one level (Grade 3) is considered, and EHL rather than English first additional language was analysed. The latter is relevant to a great many more classrooms, the subject being taken by about $80 \%$ of learners in school. Nonetheless, the EHL text is the basis for the development of other language workbook texts and thus merits close consideration. ${ }^{2}$

Because we were interested in curriculum alignment, the two relevant curriculum documents also formed part of our data set: The Curriculum and Assessment Policy Statement English Home Language Foundation Phase Grades R-3 (2011) and the Curriculum and Assessment Policy Statement Mathematics Foundation Phase Grades R-3 (2011).

The EHL workbooks consist of 125 'activities', which are essentially worksheets spread across two workbooks. Each activity covers a two-page spread and generally consists of a piece of extended text, comprehension questions, writing activities, and language and phonics tasks. In some of the activities, a category titled 'fun' includes games or puzzles for learners to complete. The activities are divided into eight themes, with two themes being covered per term. Each theme is preceded by a one-page overview of what is covered in each of the activities in the theme.

The mathematics workbooks consist of $138^{3}$ numbered activities across the two workbooks. Each activity has a heading and spreads across two pages, with numbered tasks on each page. Each numbered task has its own subheading or instruction. In general, the tasks on the second page of the activity extend or build on the tasks given on the first page of the activity.

The unit of analysis was the task. A task is defined as an activity with a single goal or theme that the learner is required to complete. It may refer to a single action (such as reading an extended piece of text) or a number of actions (completing six multiplication sums). For EHL, 593 tasks were identified across the two workbooks. In mathematics, there were 613 tasks across the two workbooks.

\section{Conceptual framing}

There were two central features of our analysis of the workbooks. The first was curriculum alignment and the second considered the structuring of the content in the workbook. In relation to alignment, we focused on coverage of curriculum contents in the workbooks, and the weighting given to different content. In relation to the structuring of content in the workbooks, we considered 'conceptual signalling' in the books and progression.

2 Because the focus is on English the study cannot pick up on one of the most widely reported problems in the workbooks (albeit anecdotal): that of poor translation. reported problems in the workbooks (albeit anecdotal). that of poor translation. Further, Mackay (pers. comm., 2015), reports that one of the central problems encountered with African languages 'pertains to the lack of standardization of the African languages and the fact that many language teachers expect the text to be the language/dialect that they "speak".

3.Ten of the 128 Workbook Activities are labelled a and b. These have been counted separately. 
Following Bernstein (1996), at the heart of any pedagogic activity is evaluation. 'Evaluative criteria' are those criteria that are to be taught and learnt, or the criteria according to which teaching can lead to the production of the legitimate text on the part of the learner. Recently, there has been much focus on the 'visibility' or explicitness of criteria in teaching and learning situations (Hattie 2009; Morais et al. 2004), with much of it arguing for 'making the evaluative criteria explicit', in other words making the content, concepts and skills, and what students are required to do with them, clear. It consists of 'clearly telling children what is expected of them, of identifying what is missing from their textual production, of clarifying the concepts, of leading them to make syntheses and broaden concepts ...' (Morais et al. 2004:8). Although much of this research refers specifically to classroom practices, the notion of explicit evaluative criteria is relevant to pedagogic texts, like the workbooks. In this regard, the extent to which a text makes the concepts being taught explicit, what is required of students, and what an appropriate production on the part of a learner might look like, has bearing on the type of curriculum tool that text represents.

In relation to evaluative criteria, we analysed what we call 'conceptual signalling' across the books. Conceptual signalling refers to how concepts/content/skills underpinning tasks or activities are made explicit or left implicit. Conceptual signalling may occur in explanatory text, headings, subheadings, text boxes and teacher notes, or it may only be implicitly read through a set of given tasks.

Along with conceptual signalling in the workbooks, we were also interested in progression. In general, across a course of study, learners will develop, consolidate and extend their understanding; in other words, progress. A curriculum document entails progression, usually elaborated through increasing levels of cognitive demand and content complexity, over the course of a year for a particular grade. We were interested in the extent to which content progression is explicit in the workbooks. In short, we used curriculum alignment (content coverage and weighting), conceptual signalling and content progression as the dimensions against which to evaluate the workbooks as effective practice, assessment and monitoring tools.
Table 2 sets out the dimensions of analysis, with related indicator and empirical variables, as well as the coding scheme that we used.

Below we elaborate further how we used this framework in the analysis.

\section{Method \\ Curriculum alignment}

Research around issues of curriculum alignment has grown recently, particularly in relation to the introduction of standardised testing (Porter \& Smithsom 2001). In our analysis of the alignment between the CAPS and the workbooks we deploy a relatively simple and direct way of measuring alignment, looking at content coverage, weighting and cognitive demand (the latter in a limited way). The CAPS documents were scrutinised for the specification of content, and topics and subtopics were extracted and listed. Indications of the weighting of topics and subtopics were also extracted from the mathematics document (where weighting is explicitly stated) and language document (where weighting is suggestive).

For mathematics and language we tabulated all the tasks in the workbooks in MS Excel. We identified each task in relation to CAPS curriculum content topics and sub-topics. In certain cases we included a further qualitative category for analysis that captured the component of cognitive demand (e.g. in EHL we looked at the length and complexity of texts, and the nature of comprehension questions. In mathematics number range was important in this regard).

\section{Conceptual signalling}

Conceptual signalling was analysed by considering whether the concepts/content/skills underpinning tasks or activities were made explicit or left implicit. Conceptual signalling may be made explicit through explanatory text, headings, subheadings, text boxes and teacher notes. Or it may only be possible to derive the underpinning concept/content/ skill by reading it off a set of given tasks (implicit).

TABLE 2: Analytic framework for analysis of workbooks.

\begin{tabular}{|c|c|c|c|}
\hline Dimension & Indicator variable & Empirical variable & Coding \\
\hline Curriculum Alignment & $\begin{array}{l}\text { The extent to which curriculum } \\
\text { content is covered and } \\
\text { appropriately weighted }\end{array}$ & Curriculum topics and subtopics covered & $\begin{array}{l}\text { Strong: Most of the curriculum topics are covered and weighted } \\
\text { appropriately across the two workbooks. } \\
\text { Moderate: A reasonable proportion of the topics are covered with } \\
\text { reasonable weighting across the two workbooks. } \\
\text { Weak: Not all curriculum topics are covered across the two } \\
\text { workbooks, or there is disproportionate weighting. }\end{array}$ \\
\hline Conceptual Signaling & $\begin{array}{l}\text { The extent to which content/ } \\
\text { concepts/skills being taught are } \\
\text { made explicit. }\end{array}$ & $\begin{array}{ll}\text { - } & \text { Headings of tasks } \\
\text { - } \quad \text { Task instructions } & \text { Examples or model answers }\end{array}$ & $\begin{array}{l}\text { Strong: Conceptual signaling is explicit and discrete content/ } \\
\text { concepts/skills underlying tasks are discernible. } \\
\text { Moderate: Conceptual signaling is sometimes explicit and } \\
\text { sometimes discrete content/concepts/skills underlying tasks are } \\
\text { discernible. } \\
\text { Weak: Conceptual signaling is seldom explicit and discrete content/ } \\
\text { concepts/skills underlying tasks are seldom discernible. }\end{array}$ \\
\hline Progression & $\begin{array}{l}\text { The change in cognitive demand } \\
\text { and content complexity from more } \\
\text { simple to more complex/ } \\
\text { challenging }\end{array}$ & $\begin{array}{l}\text { - Levels of cognitive demand of tasks } \\
\text { Levels of content complexity }\end{array}$ & $\begin{array}{l}\text { Strong: There is clear increase in the complexity of content and } \\
\text { difficulty of task demands across the activities from the beginning } \\
\text { of Workbook } 1 \text { to the end of Workbook } 2 \text {. } \\
\text { Moderate: There is some increase in the complexity of content or } \\
\text { difficulty of tasks across the activities in the two workbooks, but this } \\
\text { is either not consistent or the increase is slight. } \\
\text { Weak: There is little difference in the complexity of content or } \\
\text { requirements of tasks from the beginning of Workbook } 1 \text { to the end } \\
\text { of Workbook } 2 \text {. }\end{array}$ \\
\hline
\end{tabular}


Conceptual signalling was coded as weak (implicit) or strong (explicit) as per Table 1 .

\section{Progression}

To analyse progression, we extracted all the workbook tasks listed under each of the topics or subtopics in the Excel sheet, and considered them vertically, that is, how each topic appeared sequentially across the workbooks. The questions driving the analysis here were: Do the tasks indicate increase in the cognitive demand over the course of the workbooks? Does the complexity or challenge of the content/concept/skills introduced increase over the course of the tasks as presented in the workbooks? We then made a global judgment of the strength of progression as weak, moderate or strong in relation to both content and task demand of particular topics.

On the basis of this analysis, of curriculum alignment, progression and conceptual signalling, we make an argument around the types of pedagogic tools that the workbooks in their current form represent, and what some of the system and other implications are, that flow from this.

\section{Findings: English Home Language workbooks}

\section{Curriculum alignment between CAPS EHL and the EHL workbooks}

CAPS EHL has four main language curriculum content areas: 'listening and speaking'; 'phonics'; 'reading and viewing'; 'handwriting and writing'. At this broad level, there are differences between the CAPS EHL and the EHL workbooks. Firstly, while CAPS EHL suggests that content related to language structure and use, especially grammar, be integrated into the teaching of other areas, in the workbooks this content appears in isolated tasks. Secondly, handwriting and listening as particular skill sets do not feature in the workbooks. Aside from these aspects, the EHL workbooks comprehensively cover the content areas specified in the EHL CAPS. The curriculum areas of 'speaking', 'reading and viewing', 'phonics' and 'writing' are each considered briefly below in relation to content coverage.

\section{Speaking}

Overwhelmingly, the focus of activities concerned with developing children's oral acuity is on using visual representations to predict narrative text. 'Speaking' is largely constituted as a pre-reading, text-prediction activity. There are very few speaking activities following the reading of text, and none directly following a reading. The emphasis in the CAPS document is on student response and reasoning around the meaning of a read text. The EHL workbooks do not include directed pre- and post-reading questions based on detailed semantic aspects of readings. ${ }^{4}$

\footnotetext{
4.As we shall see below, the workbooks were not intended and do not function to replace ordinary class teaching and reading activity which would include this type of questioning. McKay (pers. comm., 2015) however, suggests that questions are questioning. McKay (pers. comm., 2015) however, suggests that questions are
planned for the backs of proposed graded readers and on the inner covers of big books that are being developed that will be distributed to teachers.
}

\section{Reading}

Three sub-topics of reading were identified in the task analysis considering coverage: extended reading texts; reading comprehension exercises; and sight words.

For our purposes, extended text was defined as text comprising more than five sentences. In EHL Workbook 1, there are 29 extended texts, and in EHL Workbook 2, there are 23 . The texts range from 6 to 29 sentences and vary in the complexity of the text in relation to tense, sentence structure, language features and vocabulary. Of the total 62 extended texts, 55 are fiction texts and 7 non-fiction texts. Given that learners will need to access meaning in a wide range of nonfiction genres in Grade 4, such as procedures in science, diagrams and charts in Geography and Science, etc., the number of extended non-fiction texts is very limited. ${ }^{5}$ The format for the fiction texts is predominantly narrative (31 of the 62 texts), with some characters repeated across different texts. A range of text types, such as diary entries, postcards, a news report, are included. None of the texts are original extracts from literature, popular media, poetry and so on. While this may be due to the expense of reproducing copyright material, it does mean that there is a lack of variation in the style, tone and structure of the text.

Students are exposed to a substantial amount of text that is generally grammatically sound and free of error. Texts generally deploy language and experiences that learners would be familiar with, hence the focus of so many of the texts on the school as a setting. The meaning of texts is generally simple, straightforward and focused on mundane experiences, for example, 'back to school', 'uniforms', 'animals', and 'the four seasons'.

Most of the extended texts are followed by a comprehension exercise of 4 to 5 questions. These questions were coded according to five comprehension question types suggested in the EHL CAPS document. These are questions that required literal comprehension; reorganisation; inference; evaluation and appreciation. While the EHL CAPS requires an emphasis on higher order questions (reorganisation; inference; evaluation and appreciation), most questions in the workbooks were literal (106 out of a total of 176 questions across 47 comprehension tasks, or $60 \%$ of the total number of comprehension questions students were required to answer were 'literal' involving simple factual recall from the text).

\section{Writing}

According to the EHL CAPS document, by the end of Grade 3 learners should be competent writers of extended text, able to use a range of tenses, to use correct spelling and punctuation. They should also be able to recognise and write in a range of writing formats. The CAPS document suggests that students be taught processes of planning and editing writing and should be made aware of sequencing and developing a logical narrative.

5.Although a wide range of non-fiction topics are addressed in the life skills workbooks, there are very few extended non-fiction texts in the workbooks for English, with almost no tasks that require learners write extended text in a non-fiction genre. 
The workbooks provide plenty of writing opportunities in a wide range of writing formats. Twelve activities require learners to write extended text. A further 27 tasks require the writing of one to two paragraphs and 75 tasks require that learners write about 5 sentences, usually using given words that incorporate a particular language or grammatical feature. Learners are required to practice different genres (e.g. writing narrative text, cards, invitations, etc.). Again, the absence of extended writing in a non-fiction mode or scientific genre is notable.

\section{Phonics}

The EHL CAPS document specifies that Grade 3 students consolidate Grades 1 and 2 phonics. Furthermore, they need to be able to recognise consonant digraphs, consonant blends and vowel digraphs, as well as the silent e or split digraph. They need to be able to recognise and use more complex spelling patters (e.g. -igh [high], -ough [tough], and silent letters in words, ' $k$ ' in ' $k$ now'). They need to recognise hard and soft sounds of ' $c$ ' and ' $\mathrm{g}$ '. They are required also to recognise rhyming words, be able to break down and build up simple words, recognise prefixes and suffixes, and group words into word families according to their onset and rime. The workbooks systematically address all of these EHL CAPS requirements. Phonics is explicitly taught in 66 of the 125 activities. There is recycling of particular phonics aspects. For example, more complex diagraphs, such as the/ph/for ' $\mathrm{f}$ ' sound, are introduced multiple times across different activities. Phonics introduced are highlighted in the extended reading texts.

\section{Language structure, use and grammar}

In the CAPS curriculum, language structure, syntax, rules of use and grammar as a curriculum content area do not feature separately. These aspects are meant to be integrated into the other areas, in particular reading and writing. Most of the EHL CAPS expectations around the understanding and use of parts of speech and grammar elements are specified under the curriculum section 'handwriting and writing'. According to the curriculum, by the end of Grade 3, learners should have been exposed to a range of sentence structures in English and should be able to understand and use different tenses. They should also have practise in verbsubject agreement in English and the use of punctuation, conjunctions, nouns, pronouns, adjectives, verbs, adverbs and prepositions correctly. They should also be familiar with parts of speech. They should understand the difference between questions, statements and commands, and they should be able to identify synonyms and antonyms.

Coverage of these aspects of language in the workbooks is comprehensive. All specified language elements in the EHL CAPS are covered in the workbook. Language structures are also recycled across activities. For example, tense (future, past, irregular past, present) is dealt with in 18 different activities. Language, sounds, sight words and spelling are, however, contrary to the EHL CAPS requirements, taught separately from extended text readings and comprehension tasks. This potentially restricts students' understanding that these language features have real textual function and meaning (see also NEEDU 2013).

\section{Summary - Curriculum alignment language}

There is no specification of weighting of curriculum content areas in the EHL CAPS document. A count of tasks relevant to particular topics in the workbooks indicates, however, a range and spread of tasks across the curriculum content areas. The emphasis in the workbooks is on reading and writing. The workbooks do not cover handwriting or listening as skill areas. They do not deal explicitly with vocabulary development. However, considering the writing, language structure, use and grammar and phonics components especially, the workbook represents comprehensive compliance with the EHL CAPS curriculum.

\section{Conceptual signalling}

Conceptual signalling, which indicates the underlying language skill/content/concept being taught, can be either explicit or implicit. There is no signalling of what is to be learnt in the headings, subheadings or body text of the EHL workbooks. In the text there are a few indications of the primary learning component. Where this does occur it mostly consists of language or grammar components being defined. ${ }^{6}$ These definitions are few, however, and not consistently provided. The overviews that appear at the beginning of each of the eight themes provide very brief notes on each of the activities in the theme. In both EHL Workbook 1 and EHL Workbook 2 the teacher notes are incomplete. The teacher notes in Workbook 1 provide some of the conceptual underpinning of the activities (e.g. it specifies the phonemes being addressed). In Workbook 2, however, the notes generally repeat the instructions given in the text rather than giving further detail about skills/concepts embedded in the activity's text or tasks. The difference between EHL Workbook 1 and EHL Workbook 2 suggests that the overall purpose of the overviews is not clear.

The broader language-learning purposes of the extended texts are mostly implicit (e.g. tense, narrative structure) and are generally not spelt out in the text or in the teacher notes. Most extended texts have highlighted words, however, which refer to the words taught in the phonics section.

In short, conceptual signalling in the EHL Workbooks is not strong. The concepts/skills/language components underpinning most tasks and texts are not made explicit.

\section{Progression in the EHL workbooks}

Using the indicators outlined in the analytic framework above, we found progression to be uneven across the main curriculum language content areas identified in the EHL Workbooks.

$6 . W e$ are not referring here to the icons that direct the learner to a particular curriculum area, for example, 'reading', 'speaking', 'writing', but rather to the curriculum area, for example, 'reading', 'speaking', 'writing', but rather to the
language components being introduced, for example 'past perfect', or the specific language components being introduced, for
sound or vocabulary set being developed. 
In the 'reading' components identified in the workbooks, progression is evident in the length and complexity of texts across EHL Workbook 1. Beginning with simple texts with few and simple sentences, the passages build in length and include more complex tenses and language features. The development is less clear from EHL Workbook 1 to EHL Workbook 2, although there are more non-fiction texts in EHL Workbook 2 and a greater range in text formats (emails, maps, etc.). Progression from Workbook 1 to Workbook 2 would appear to be based not on the length or difficulty of the texts, but on a broadening range of concepts dealt with in the texts (pollution, time, a road accident) and a requirement that learners extract and apply understanding of the texts in different ways (e.g. tabulate information, create a mindmap), thus incorporating higher order activities. For progression in relation to content complexity for reading, we code the workbooks strong.

Comprehension questions are useful indicators of progression in relation to cognitive demand. As indicated above, questions remain predominantly at the literal level across both books, and the number of questions in each activity remains about the same. As indicated above, however, more questions in Workbook 2 require that learners extract and process information or apply information in the texts. We therefore code progression in cognitive demand moderate in relation to reading.

The writing activities are similar in specification and explicit task demand. They are pitched at the same level across the workbooks, in terms of length of writing as well as the use of particular language structures, topics and writing formats. Progression in terms of conceptual demand therefore is coded weak with respect to writing.

In the 'phonics' language area, content complexity increases across the workbook, and the task demands shift to some extent as well. There is an increasing emphasis on synthetic phonics (segmentation and blending of sounds in words) across the workbooks. There is a clear progression across the two workbooks, working from simpler consonant and vowel blends and diagraphs to more complex ones, silent letters and complex spelling patterns. The cognitive demand of tasks also progress from simpler recognition and use activities to matching, sorting and identifying tasks, and in EHL Workbook 2, word building activities. Progression for increasing complexity of both content and task demands is coded strong for 'phonics'.

In the curriculum content area of language structure, use and grammar, a greater range is introduced as the workbook progresses. Progression here is neither clear in the task demands, nor signalled in progressively complex content. Rather there is progression in that students are exposed to a progressively greater range of language structures and use. Progression is coded moderate for both dimensions.
TABLE 3: Progression in the EHL workbooks across language content areas.

\begin{tabular}{lll}
\hline Variable & Content complexity & Strong \\
\hline Reading & Cognitive demand & Moderate \\
Writing & Content complexity & Not applicable \\
& Cognitive demand & Weak \\
Language & Content complexity & Moderate \\
& Cognitive demand & Moderate \\
Phonics & Content complexity & Strong \\
& Cognitive demand & Strong \\
\hline
\end{tabular}

TABLE 4: CAPS Recommended number of lessons per Content Area for Grade 3 Mathematics.

\begin{tabular}{lcc}
\hline Content area & $\begin{array}{c}\text { Number of lessons } \\
\text { for year }\end{array}$ & $\begin{array}{c}\text { Proportion of total lessons } \\
\text { for the year (\%) }\end{array}$ \\
\hline $\begin{array}{l}\text { 1. Numbers, Operations and } \\
\text { Relationships }\end{array}$ & 94 & 59 \\
2. Patterns, Functions and Algebra & 16 & 10 \\
3. Space and Shape (Geometry) & 19 & 12 \\
4. Measurement & 23 & 14 \\
5. Data Handling & 8 & 5 \\
\hline Total & $\mathbf{1 6 0}$ & $\mathbf{1 0 0}$ \\
\hline
\end{tabular}

Table 3 summarises the foregoing analysis.

Overall, one can conclude that progression in the EHL workbook is moderate to strong, but weaker in relation to the undifferentiated task demands of writing activities.

\section{Findings: Mathematics workbooks content areas}

\section{Curriculum alignment between CAPS mathematics and the mathematics workbooks}

The analysis of the mathematics workbooks proceeds in much the same way as that for the language workbooks. Individually numbered tasks were organised into curriculum categories and topics. In the first instance, the analysis considers coverage of content areas in terms of the CAPS recommendations. This is followed by a discussion of each content area in terms of conceptual signalling and progression.

CAPS identifies five content areas in mathematics and provides a recommended number of lessons per week to be spent on each content area. This translates into the following proportion of time to be spent on each content area across the year (see Table 4 ).

Each activity in the workbooks covers either one or two main curriculum content areas shown in Table 4 per activity. The tasks within the activities cover the sub-topics within the content areas. Below, each of the content areas is discussed in more detail in terms of coverage of topics and sub-topics.

\section{Numbers, Operations and Relationships}

In CAPS, topics within Numbers, Operations and Relationships are grouped under three broad categories of Number Concept Development, Solving Problems in Context, and Context Free Calculations.

Numbers, Operations and Relationships is covered in more than 50 double page activity spreads in both workbooks. Tasks for 
each of these activities were coded for coverage of the topics shown in Table 5.

The workbooks systematically address all topics in Numbers, Operations and Relationships. Solving problems in context are integrated into these activities. Money and measurement are frequent contexts for addition, subtraction, repeated addition leading to multiplication and grouping or sharing leading to division tasks. CAPS identifies a range of 'problem types' for solving problems in context, and the workbooks include most of these types, like arrays, repeated addition, rate, change, combine etc. Most often the contextual problem posed as a word problem comprises a task at the end of the activity, and relates to the content focus of the activity.

There are 11 activities focused on fractions. These tasks provide substantial opportunity for learners to practice recognition of fractions in wholes and collections, as well as recognising equivalent fractions. While reading and writing fractions in symbolic form is limited, this is not an explicit requirement in CAPS for Grade 3.

In general, the workbooks provide extensive opportunities for practicing Numbers, Operations and Relationships in different number ranges and contexts, as well as practice in developing different calculation strategies.

\section{Patterns, Functions and Algebra}

Patterns, Functions and Algebra is covered in 32 double page spread activities across the two workbooks. Only two of these cover geometric patterns. Predominantly, learners are required to copy, extend and describe numbers sequences, and identify number patterns in grids and tables. The latter includes completing multiplication tables as well as tasks that involve counting in intervals. The coverage of geometric patterns is very limited, possibly because in CAPS the cognitive demand level is low and the range of tasks is thus circumscribed.

TABLE 5: Topics for Numbers, Operations and Relationships in CAPS.

\begin{tabular}{ll}
\hline Category & Topics \\
\hline Number concept development & $\begin{array}{l}\text { Count objects; count forwards or } \\
\text { backwards; number symbols and number } \\
\text { names; describe, compare and order } \\
\text { numbers; properties of numbers and } \\
\text { operations; place value }\end{array}$ \\
\hline Solving problems in context & $\begin{array}{l}\text { Problem-solving techniques; addition and } \\
\text { subtraction; repeated addition leading to } \\
\text { multiplication; grouping and sharing } \\
\text { leading to division; grouping and sharing } \\
\text { leading to fractions; money }\end{array}$ \\
Context-free calculations & $\begin{array}{l}\text { calculation techniques; addition and } \\
\text { subtraction; repeated addition leading to } \\
\text { multiplication; division; fractions }\end{array}$ \\
\hline
\end{tabular}

\section{Space and Shape (Geometry)}

Space and Shape is covered by only ten activities across the two workbooks focused on 2-D shapes, 3-D objects, position and views and symmetry. These activities provide very limited opportunities for practice in this content area, and coverage is much less than recommended by CAPS. For example, only three short and very simple activities require learners to answer questions about the position of objects or views of an object.

\section{Measurement}

Measurement is covered by 16 activities across the two workbooks, covering the topics time, length, mass, capacity, volume, area and perimeter. These provide limited opportunities for practice in this content area (e.g. length, mass and capacity are covered in only three activities for each). In Workbook 2, standard measurement units are used in problems where learners have to solve problems in context, familiarising learners with the use of these measures. Solving measurement problems in context, as part of number concept development, assumes that learners have had extensive practical experience with measurement, both with informal units and standard measures.

\section{Data handling}

Only five activities across the workbooks cover this content area, with only one of these in Workbook 2 . Tasks for each of these activities were coded for coverage of the following subtopics: collect and organise data; represent data; and analyse and interpret data. Although the cognitive demand for this content area is not high, the few activities provide very little opportunity for practice in this content area. They are all very similar in form and question types, offering little variety to learners.

\section{Summary - Curriculum alignment mathematics}

If we take an activity, i.e. a double page spread, to constitute a lesson, then the proportion of curriculum content areas covered in the workbooks are shown in Table 6 This proportion is shown alongside the recommended proportion calculated in the CAPS shown in Table 4. In this way, the extent of curriculum alignment between the CAPS and the mathematics workbooks is coded.

Compared to the recommended coverage and weighting in CAPS, a greater proportion of coverage is spent on Number, Operations and Relationships (62\% as opposed to recommended $59 \%)$ and Patterns, Functions and Algebra (19\% as opposed to

TABLE 6: Curriculum alignment in mathematics workbooks across content areas.

\begin{tabular}{|c|c|c|c|c|}
\hline Content area & $\begin{array}{c}\text { Number of activities in } \\
\text { workbooks }\end{array}$ & $\begin{array}{l}\text { Proportion of activities focused on } \\
\text { topics in workbooks }(\%)\end{array}$ & $\begin{array}{l}\text { Weighting of topics in } \\
\text { CAPS (\%) }\end{array}$ & Curriculum alignment \\
\hline 1. Numbers, Operations and Relationships & 106 & 62 & 59 & Strong \\
\hline 2. Patterns, Functions and Algebra & 32 & 19 & 10 & Strong \\
\hline 3. Space and Shape (Geometry) & 10 & 6 & 12 & Weak \\
\hline 4. Measurement & 17 & 10 & 14 & Moderate \\
\hline 5. Data Handling & 5 & 3 & 5 & Moderate \\
\hline Total & 170 & 100 & 100 & - \\
\hline
\end{tabular}


recommended 10\%), at the expense of the other three content areas. In particular, half the recommended proportion of coverage is spent on Space and Shape (6\% as opposed to recommended $12 \%)$. As discussed above, in some content areas, key topics and sub-topics are poorly covered offering limited opportunities for practice.

\section{Conceptual signalling}

In most cases, conceptual signalling that indicates the underlying content area or sub-topic to be taught and learnt is clearly signalled in the activity headings. e.g. 'Counting to $999^{\prime}$ or 'Sharing leading to fractions' or 'measuring length' etc. Conceptual signalling through definitions is seldom provided (less than five times). A further strategy for conceptual signalling used in the workbooks is 'talking heads' of learners, who provide explanations for solving problems alongside the mathematical inscriptions. 'Talking heads' occur in 32 tasks in Workbook 1, and in only 12 tasks in Workbook 2. While some of these 'talking heads' serve as useful conceptual indicators, they are not consistent and many of them actually just pose questions e.g. 'Do you see the pattern?' 'How shall I place them?'

Overall, conceptual signalling in the Mathematics Workbooks is moderate. The content/concepts/skills/components underpinning most tasks are made explicit in headings, but instructions are not always clear and definitions and worked examples occur only occasionally.

\section{Progression}

Below, each of the content areas is discussed in more detail in terms of progression.

Numbers, Operations and Relationships: Progression in Numbers, Operations and Relationships happens through increasing the number range, introducing different kinds of numbers, and developing more efficient strategies for calculations. There is clear progression from Workbook 1 to Workbook 2. Number concept development progresses through increasing the number range from activities limited to $<50$ and up to 600 in Workbook1 to mostly 3-digit number work in Workbook2 up to 1000, which is the appropriate number range in Grade 3. This is appropriately scaffolded, with the number range increasing more rapidly for counting tasks, ordering and comparing numbers and number patterns, while increasing number ranges are introduced more slowly for solving problems in context and context free calculations.

Before learners are expected to add and subtract with increasing number ranges, they work with place value and a range of different problem-solving techniques and calculation strategies. For repeated addition leading to multiplication, and for division, the number range is limited to problems involving answers up to 100 . This is consistent with CAPS specifications. There is also clear progression in number range from Workbook 1 to Workbook 2 in terms of context free calculations and writing number sentences with appropriate number symbols. Overall, progression for Numbers, Operations and Relationships is strong with respect to both cognitive demand and content complexity.

Patterns, Functions and Algebra: Although there is progression with respect to increasing number ranges that learners have to work with, the repetitive nature of activities for Patterns, Functions and Algebra limits variation in terms of question types and tends to proceduralise responses. Thus, for this content area, learners are not exposed to progressively more complex forms of reasoning. Many of the tasks have exactly the same format, sequence of questions and number range. Progression in this content area is moderate.

Space and shape (Geometry): Progression in CAPS for Shape and Space entails mostly the addition of new 2-D shapes or 3-D objects. CAPS also assumes that learners will have lots of opportunity to manipulate, touch and feel shapes and objects. Learners are introduced to most of the shapes and objects early on in Workbook 1 . There is not a progressive introduction of different shapes or objects and the activities show little variation in relation to the cognitive demands posed by the tasks. Progression in this content area is weak.

Measurement: There is evidence of progression with respect to Measurement in that the activities in Workbook 1 focus on non-standard units of measurement, while in Workbook 2, standard measures are introduced and used in activities. Progression is also evident in increasing complexity of contexts in which the passing of time has to be calculated. However, the format of questions relating to measurement is often the same, limiting the range of complexity and tending towards proceduralising responses. Progression is moderate.

Data handling: There are only five activities in total dealing with Data Handling and there is no significant progression in cognitive demand or content complexity from the first data handling activity to the last.

Summary - progression mathematics: The Table 7 summarises progression in the different content areas in the Mathematics workbook for both levels of cognitive demand and content complexity:

In short, progression in the Mathematics workbook varies across the different content areas, but is strong in relation to the key content area of both the CAPS and the workbooks, namely Numbers, Operations and Relationships.

TABLE 7: Progression in the mathematics workbooks across content areas.

\begin{tabular}{ll}
\hline Content area & Progression \\
\hline 1. Numbers, Operations and Relationships & Strong \\
2. Patterns, Functions and Algebra (geometric and number patters) & Moderate \\
3. Space and Shape (Geometry) & Weak \\
4. Measurement & Moderate \\
5. Data Handling & Weak \\
\hline
\end{tabular}




\section{Discussion}

The mathematics and EHL workbooks as curriculum tools. Having analysed the workbooks in terms of curriculum alignment (coverage and weighting in particular) and content structure (conceptual signalling and progression), below we consider the ways in which the workbooks conform to the curriculum tools introduced earlier.

Practice tool: Where pedagogic texts function as a curriculum practice tool, they offer multiple opportunities for learners to practice the same or similar contents and skills. A practice tool assumes that content has been introduced elsewhere and that conceptual understanding of contents is already in place. The focus is thus on the rehearsal of contents, concepts and skills. As a practice tool contents and skills are re-visited, sometimes increasing in complexity or cognitive demand.

As a practice tool, the EHL workbooks offer multiple opportunities for learners to read and engage with texts systemically. However, this is at a relatively basic level. The range of texts (especially non-fiction texts) is limited. The texts are straightforward with an emphasis on narration and description as opposed to argumentation or exposition. The texts focus on mundane and familiar themes. In this way, the texts do not facilitate the drawing of inferences or making of evaluations - key comprehension skills shown to be most absent in learner assessments of language (Howie et al. 2008). Comprehension tasks also consist predominantly of questions at a 'literal' level of understanding.

The EHL books provide extensive opportunities for practicing writing in a wide range of writing formats. This includes writing extended text. The EHL workbooks offer extensive opportunities for the practice of phonics and language structures, moving from more simple to more complex identification and usage. The workbooks are less effective as a practice tool for sight words, as these generally occur in isolation without attendant tasks. Overall, wellaligned with the CAPS, the EHL books constitute a tool for practicing the range of language curriculum content reading, writing and speaking the language and engaging with a range of sentence structures, tenses and grammatical forms. It does not provide for practice in new vocabulary, listening or handwriting.

As a practice tool the Mathematics workbooks are effective for practicing Numbers, Operations and Relationships and Patterns, Functions and Algebra. For both these content areas they provide a solid resource for practice and consolidation, with clear progression and scaffolding of concepts and skills to be acquired. More than $80 \%$ of the activities cover these two content areas, offering multiple opportunities for learners to practice reading, representing, ordering and comparing numbers, performing calculations and solving problems in context within grade appropriate number ranges. The mathematics workbooks, however, offer limited opportunities for practicing content and skills for Space and Shape, Measurement and Data Handling. Activities from these content areas are sparsely distributed across the workbooks, providing only moderate engagement with these content areas in a term.

The EHL and mathematics workbooks overall are wellaligned with the Grade 3 CAPS curriculum. They are strictly grade level texts, with no differentiated learning opportunities. However, were additional workbooks provided to schools, they could offer a potential resource for remediation of learners who have fallen behind, particularly in extended school time (e.g. a learner in Grade 3 who is not working at Grade 3 level could potentially work through the Grade 1 and Grade 2 workbooks in afternoon classes or as homework). Likewise, workbooks of the following grade could be used for the extension of learners who are capable of more challenging tasks.

Assessment tool: Considered as an assessment tool, both the EHL and Mathematics workbooks are inconsistent in the extent to which they make the contents or concepts underpinning tasks explicit. In other words, they are not always clear regarding what might be assessed in a particular task. Especially in EHL, evaluative criteria are implicit. Furthermore, there are no activities that draw together tasks from discrete content areas to be completed in one activity (in other words, they do not model assessment texts). In neither EHL nor Mathematics workbooks are model answers, solutions or assessment rubrics provided. In the Mathematics workbooks, 'talking heads' of children are used in some places where worked examples are given. The 'talking heads' signal different calculation strategies. There are 29 occurrences in Workbook 1 and only 12 in Workbook 2 . Furthermore, the limitations to progression in some areas of learning makes the workbooks' use in tracking the progress of learners, and as an assessment tool to diagnose whether learners require intervention as the DBE intention suggests, limited.

Monitoring tool: The overall high level of curriculum compliance of the workbooks suggests they could be effective as a monitoring tool at a systemic level. It would be possible to gain a crude measure of coverage in key content areas by calculating the number of pages completed in the workbooks. The potential of this form of monitoring is supported by the fact that full use of the workbooks in schools was made mandatory in 2014. As the NEEDU 2013 report highlights, however, this quantitative indication of curriculum coverage across classrooms will not provide any indication of the quality of work being completed nor will it give a reliable indication of learners' progress. This would require an indepth investigation of how (accurately and appropriately) students are completing the workbooks. Furthermore, the limitations of progression in the workbooks, as discussed above, preclude using the workbooks as a tool for monitoring learner performance over time in certain areas of learning. Counting the number of pages completed in the workbook will not give a reliable indication of learners' progress. 


\section{Conclusion}

The DBE's suggestion that the workbooks be used to provide learners with opportunities to practise their learning accords with our analysis and conclusion that the workbooks best represent a practice curriculum tool. Their undifferentiated nature is possibly a limitation in this regard given the number of learners in the system that requires remediation (i.e. the opportunity to practice content from previous grades) as evidenced in systemic tests. The possibilities of teachers using the workbooks to track the progress of learners and provide extra support where necessary are less likely. As an assessment curriculum tool the workbooks are limited in that evaluative criteria and conceptual signalling are often implicit (especially in language); there are no representations of model answers, solutions or gauges of what a successful learner production looks like; and the text does not model assessment items. Especially in the context of weak teacher content knowledge (Venkat \& Spaull 2014), the workbooks do not provide sufficient conceptual signalling to allow teachers to gauge and track student progress.

At the system level, the workbooks could provide a quantitative measure of curriculum coverage. They would in their current form not provide any indication of the quality of learning and teaching, and nor could they be used to assure this quality. Furthermore, the workbooks in their current form could not provide a reliable indicator of learner progress over time. However, they present a relatively simple and quick way to measure curriculum coverage at a very basic level.

Recently, there have been suggestions in some quarters that the workbooks be trialled as the sole text given to teachers. Based on our analysis, especially the limitations of conceptual signalling, we argue that using the current workbooks as a teaching or a transmission tool is not viable, and they are restricted in the extent to which they can 'structure learning activities for learners' as proposed by the DBE. In order to use the workbooks to support quality teaching they would need further development to make the evaluative criteria and conceptual signalling in the text more explicit. This could be accomplished by strengthening the teacher notes, providing more comprehensive in-text notes, producing an aligned teacher guide, or using the workbook alongside a good textbook. ${ }^{7}$ With the recent proposal to produce a single textbook per subject per grade, this textbook could usefully be aligned with the workbooks. The textbook could then function as a primary transmission text, with clear conceptual signalling as well as relevant tasks, and the workbook could function as a practice tool, either for use in class or as a homework resource.

Finally, a note on alignment: one of the key features of a good instructional regime is alignment, between the intended, the implemented and the assessed curriculum (Schmidt, McKnight \& Raizen 1996), or, to put it another way, between curriculum policy statements of required learning, the actual curricular content that students engage in the classroom, and the content that is tested. Alignment is also critical in relation to texts that support the implemented curriculum - such as textbooks and workbooks. The moderate-to-strong alignment between the CAPS and the workbooks is very positive in this regard. It opens up the possibility for alignment not only between the workbooks and other curriculum interventions, such as textbooks, but also between the workbooks and the ANAs. ${ }^{8}$ In this way, a strong statement of learning requirements (in the CAPS and ANAs), as well as support to meet these requirements (in textbooks and the workbooks), can potentially be made available to teachers in improving instructional offerings in the classroom. In a system where there is widespread learner failure, a set of strong and wellaligned curriculum elements holds great potential to support teachers in implementing the curriculum and improving learning outcomes.

\section{Acknowledgements Competing interests}

The authors declare that they have no financial or personal relationships which may have inappropriately influenced them in writing this article.

\section{Authors' contributions}

U.H. and J.G. equally contributed to the conceptualising, analysis and write up of this article. J.G. focused more intensively on the Mathematics workbooks and U.H. on the Language workbooks.

\section{References}

Australian Council for Educational Research, 2013, Formative evaluation of textbooks and workbooks in South Africa, DBE, Pretoria.

Bernstein, B., 1996, Pedagogy symbolic control and identity: Theory, research, critique, Taylor \& Francis, London.

Davis, Z., 2012, 'Homomorphisms, counting and the constitution of addition in a Grade 1 lesson', in S. Nieuwoudt, D. Laubscher \& H. Dreyer (eds.), Proceedings of the 18th National Congress of the Association for Mathematical Education of South Africa (AMESA), University of the North-West, Potchefstroom, June 25-28, pp. 100-107.

DBE, 2015, Workbooks, viewed 19 March 2015, from http://www.education.gov.za/ Curriculum/Workbooks/tabid/574/Default.aspx

Fleisch, B., Taylor, N., Herholdt, R., \& Sapire, I., 2011, 'Evaluation of back to basics mathematics workbooks: A randomised control trial of the primary mathematics research project', South African Journal of Education 31, 488-504.

Galant, J., 2013, 'Selecting and sequencing mathematics tasks: Seeking mathematical knowledge for teaching', Perspectives in Education 31(3), 34-48.

Hattie, J.A.C., 2009, Visible learning: A synthesis of over 800 meta-analyses relating to achievement, Routledge, London, UK.

Howie, S., Venter, E., van Staden, S., Zimmerman, L., Long, C., du Toit, C. et al., 2008 , PIRLS 2006 summary report, Centre for Evaluation and Assessment, University of Pretoria, Pretoria.

Mathews, C., Mdlulu, M., \& Ramsingh, V., 2014, 'The use of workbooks in South African grade 3 mathematics classrooms', South African Journal of Childhood Education 4(1), 80-94.

McLoughlin, C., 1999, 'The implications of the research literature on learning styles for the design of instructional material', Australian Journal of Educational Technology 15(3), 222-241. http://dx.doi.org/10.14742/ajet.1859

Morais, A., Neves, I. \& Pires, D., 2004, 'The what and the how of teaching and learning', in J. Muller, B. Davies \& A. Morais (eds.), Reading Bernstein, researching Bernstein, pp. 75-90, RoutledgeFalmer, London.

8.The ANAs are the first programme of national population testing across a range of grades, and were instituted in 2011. From 2011 to 2015 the ANAs have been grades, and were instituted in 2011. From 2011 to 2015 the ANAs have been
administered to all learners in Grades 1 to 6 and Grade 9 in Mathematics and Language. 
Mukundan, J. \& Ahour, T., 2012, 'A review of textbook evaluation checklists across four decades (1970-2008)', Journal of Language Teaching and Research 3(6), 1128-1134.

Porter, A. \& Smithson, J., 2001, 'Defining, developing and using curriculum indicators', CPRE research report series RR-048, Consortium for policy Research in Education, University of Pennsylvania, Philadelphia, PA.

Schmidt, W.H., McKnight, C.C. \& Raizen, S.A. (with Jakwerth, P.M., Valverde, G.A., Wolfe, R.G., Britton, E.D., Bianchi, L.J. \& Houang, R.T.), 1996, A splintered vision: An investigation of U.S. science and mathematics education. Kluwer Academic Publishers, Dordrecht, The Netherlands.
Taylor, N., 2013, NEEDU national report 2012: The state of teaching and learning literacy in the foundation phase, Department of Basic Education, Pretoria.

Taylor, N., 2014, NEEDU National Report 2013: Teaching and learning in rural primary schools, Department of Basic Education, Pretoria.

Ulbig, S., 2010, 'A Picture is Worth What? Using Visual Images to Enhance Student Engagement and Retention', International Journal of Instructional Media, 37, 2, 185-200.

Venkat, H. \& Spaull, N., 2014, What do we know about primary teachers' mathematical content knowledge in South Africa? An analysis of SACMEQ 2007, Stellenbosch Economic Working Paper 13/2014, Stellenbosch University, Stellenbosch. 